\title{
Article
}

\section{Risk assessment and relationship management: practical approach to supply chain risk management}

Ritchie, Robert, Brindley, Clare S. and Armstrong, Nick

Available at http://clok.uclan.ac.uk/5198/

Ritchie, Robert, Brindley, Clare S. and Armstrong, Nick (2008) Risk

assessment and relationship management: practical approach to supply chain risk management. International Journal of Agile Systems and Management, 3 (3/4). pp. 228-247. ISSN 1741-9174

It is advisable to refer to the publisher's version if you intend to cite from the work. http://dx.doi.org/10.1504/JASM.2008.021211

For more information about UCLan's research in this area go to http://www.uclan.ac.uk/researchgroups/ and search for <name of research Group>.

For information about Research generally at UCLan please go to http://www.uclan.ac.uk/research/

All outputs in CLoK are protected by Intellectual Property Rights law, including Copyright law. Copyright, IPR and Moral Rights for the works on this site are retained by the individual authors and/or other copyright owners. Terms and conditions for use of this material are defined in the policies page.

\section{CLoK}

Central Lancashire online Knowledge www.clok.uclan.ac.uk

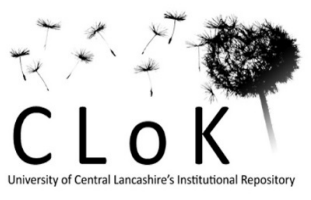


Risk Assessment and Relationship Management - Practical Approach to Supply Chain Risk Management

Professor Bob Ritchie, University of Central Lancashire

Professor Clare Brindley, Nottingham Trent University

Nick Armstrong, Research Associate, University of Central Lancashire

Correspondence to:

Professor Clare Brindley, Professor of Marketing and Entrepreneurship, Nottingham Business School, Nottingham Trent University, Nottingham NG1 4BU, UK.

Telephone : 01158484707

Fax : 011158484707

clare.brindley@ntu.ac.uk 


\title{
Risk Assessment and Relationship Management - A Practical Approach to Supply Chain Risk Management
}

\begin{abstract}
The literature suggests the need for incorporating the risk construct into the measurement of organisational performance, although few examples are available as to how this might be undertaken in relation to supply chains. A conceptual framework for the development of performance and risk management within the supply chain is evolved from the literature and empirical evidence. The twin levels of dyadic performance / risk management and the management of a portfolio of performance / risks is addressed, employing Agency Theory to guide the analysis. The empirical evidence relates to the downstream management of dealerships by a large multinational organisation. Propositions are derived from the analysis relating to the issues and mechanisms that may be employed to effectively manage a portfolio of supply chain performance and risks.
\end{abstract}

Key Words : Supply Chain Risk, Risk Management, Relationship Management, Agency Theory, Risk Management Portfolio. 


\section{Introduction}

The paper aims to evolve a holistic conceptual framework of supply chain risk management encompassing the twin dimensions of risk and performance. The Framework encapsulates risk drivers, risk perceptions and risk management, derived from the distillation of prior research and empirical findings and evaluated within a practical case setting. Supply chain risk management is crucially viewed as a portfolio of decisions, recognising that supply chain decision makers manage simultaneously a multiple set of risk encounters, rather than serially addressing single dyadic interfaces. An Agency Theory approach is employed in the conceptualisation and generation of propositions concerning effective supply chain risk management.

The paper is differentiated from previous studies in four important respects. Firstly, it recognises that management are typically handling a portfolio of risks in the supply chain, both upstream and downstream; secondly the focus is directed at strategic and tactical levels of decision taking since operational decisions are largely resolved by heuristic decision tools; thirdly we seek to explicitly address the performance and risk interface, recognising their interconnectivity; and finally we consider the holistic view of the supply chain, encapsulating inbound supply risks (Zsidisin et al, 2004), outbound demand risks ( Selen and Soliman, 2002) and the wider network risks (Harland et al, 2003).

Businesses are experiencing pressures to improve the efficiency and effectiveness of the supply chain, seeking to deliver the best value to the ultimate consumer whilst remaining competitive. Examples of strategies designed simultaneously to improve consumer satisfaction and efficiency, whilst addressing global competitive pressures, include shortening the supply chain through disintermediation (Mills and Camek, 2004), outsourcing (Lonsdale, 1999), employing JIT (Svensson, 2002) and improving business-to-business relationships (Ritchie and Brindley, 2000). Paradoxically, such strategies may well heighten the risk exposure of the organisations throughout the entire supply chain, due to increased complexity, turbulence and the dynamic and changing supply chain context (Harland et al, 2003). Increasingly, attention is being given to the wider supply chain implications, involving second and third tier suppliers, and supply chain networks, rather than simply the more direct and immediate dyadic supply and demand interactions (Harland et al, 2003; Juttner, 2005; and Zsidisin et al, 2000).

There are an almost infinite variety of definitions of the term risk (Ritchie and Marshall, 1993; Adams, 1995) depending on context and decision type. However, the present study defines supply chain risk as perceptions of the likelihood of a particular set of unwanted or undesirable performance outcomes occurring in terms of the supply chain's ability to deliver the required values to the consumer, efficiently and effectively. Risks 
may emanate from any part of the supply chain and cause increasing or diminishing effects as they transmit themselves throughout the entire chain (e.g. 'the bullwhip effect' : Lee et al , 1997). We have elected to take a more holistic view of the supply chain (Svensson, 2000; Selen and Soliman, 2002; Harland et al, 2003) in terms of the initial conceptualiSation, whilst not denying the value of focusing on particular dyadic relationships (e.g. Zsidisin et al, 2004, Juttner, 2005).

Our initial conceptual framework recognises the contribution of previous studies and the gaps still to be addressed in this relatively new field of research (Christopher and Peck, 2004). The approach highlights initially the performance-risk interface, leading to the context of Supply Chain Management, explaining the general nature of Supply Chain Risk. The section concludes with the development of the conceptual Supply Chain Risk Management Framework. The Case Study, involving multiple organisations (i.e. a portfolio of potential risk encounters or contracts between a single principal and multiple agents) is presented. An Agency Theory approach is then employed to guide the analysis and distillation of the experience of one organisation's approach to managing a strategically important part of its supply chain. A revised Supply Chain Risk Management - Portfolio Management Framework is developed and an Agency Theory approach is employed to derive a number of propositions concerning effective supply chain risk management. Conclusions and suggestions for further development of research relating to the propositions are provided.

\section{Supply Chain Risk Management : a Conceptual Framework}

Conceptually, risk and risk management are relatively straightforward constructs when dealt with in isolation from the complex, dynamic and often hostile milieu that most organisations encounter in managing their supply chains. The strategic significance of the supply chain and its effective management in terms of sustaining competitive advantage and shareholder wealth is now paramount (Hendricks and Singhal, 2003). Yet researchers have concluded that a large proportion of firms either rely on less sophisticated and robust tools, techniques and models to manage their supply chain strategies and risks or lack any coherent framework at all to guide them in developing these (e.g. Lonsdale and Cox, 1998; Juttner, 2005; Harland et al 2003).

\subsection{Risk and Performance}

Child and Faulkner (1998) suggest that decisions relating to changes in the supply chain structure and relationships ought to involve the analysis and evaluation of the associated potential benefits, costs and risks (i.e. changes sought in performance need to recognise the consequential changes in risk and vice-versa). Lonsdale and Cox (1998, p. 160) emphasised the need for 'robust implementation and supplier management tools to ensure that control is retained.' Performance and risk are interconnected and require deliberate management to maximise performance whilst controlling the consequential risks. Melnyk et al (2004, p.210) 
reflecting on metrics and performance measurement suggest that 'performance measurement continues to present a challenge to operations managers as well as researchers of operations management.' We employ a definition in the current paper that mirrors the performance dimensions of the Balanced Scorecard (Kaplan and Norton, 1992, 1996) incorporating the Financial Perspective, the Internal Perspective, the Customer Perspective and the Innovative and Learning Perspective.

\subsection{Supply Chain Management}

The field of Supply Chain Management is a diverse one encompassing a variety of different paradigms and perspectives (e.g. Christopher, 2000; Nassimbeni, 1999; Giannakis et al., 2004). Other research (see Selen and Soliman, 2002) has sought to differentiate the Supply Chain (i.e. the upstream components) from the Demand Chain (i.e. the downstream components). The present paper takes a more holistic view, questioning the value of differentiating between supply-side and demand-side when assessing the impact on aggregate performance and risk, since the chain itself represents a contiguous series of linkages and relationships. The term Supply Chain is defined to encompass all of the structures, people, processes and systems engaged throughout the chain from primary resource suppliers to the final consumer. Consequently, Supply Chain Management relates to the effective and efficient management of the entire chain in satisfying the ultimate consumer needs. The limitations on any single organisation to influence the more distant parts of the chain are fully recognised.

\subsection{Supply Chain Risk}

Most definitions of the term risk share three dimensions (Ritchie and Marshall, 1993):

\section{- $\quad$ Likelihood of occurrence of a particular event or outcome}

- $\quad$ Consequences of the particular event or outcome occurring

- $\quad$ Sources and Causal Pathways leading to the event

Each may be measured in different ways depending on the situation. The likelihood, usually expressed as the probability of occurrence, can be formulated in objective or subjective measures. Consequences may employ single or multiple measures simultaneously (e.g. the failure of the quality assurance system may generate consequences for the organisation's reputation, financial performance and exposure to legal redress). The consequences from risk taking should not only be framed in negative terms, since the essence of risk taking is usually the potential opportunity to produce positive outcomes (i.e. rewards). The third dimension, the sources and causal pathway has important implications for risk management, since it relates to the nature, sources and causes that generate the pathway of events, influences the likelihood and ultimately determines the scale of the consequences. Risk triggers are often associated with sources and causal pathways (e.g. 
Harland et al, 2003) representing the conditions which may release the latent risk source. The term risk driver is used in the present paper as a generic term to represent these triggers, sources and causal pathways.

Risk Management is seen as the range of activities that may be taken to avoid the occurrence of an undesirable event or to modify, minimise, or eliminate the consequences should the event occur. This diversity of potential actions, outcomes and measurement systems reflects the real-life complexity facing the supply chain risk management process. Harland et al (2003, p.60) concluded from their empirical study that 'risk management at the level of the network proved very difficult' for the organisations involved.

Uncertainty is often regarded as a special case of the risk construct, in which the decision maker is faced with insufficient information, knowledge or understanding to identify all of the potential risk drivers, likelihoods or consequences. More usually, the terms risk and uncertainty are employed interchangeably, as typically risk contexts are often somewhere in the middle of this risk-uncertainty spectrum. Other terms such as ‘vulnerability’ (Peck, 2005) and ‘disturbance’ (Svensson, 2000) are used to describe the risk and uncertainty present in the supply chain.

Other important issues associated with risk management include:

- $\quad$ The ex-post perspective, or after-the-event view, is a common approach to analysing risk drivers, exposures and consequences (Ritchie and Marshall, 1993). Whilst decision makers may arguably gain knowledge, understanding and experience to aid future decisions, this is not the more usual perspective experienced in managing current risks in the supply chain.

- $\quad$ The ex-ante perspective is a more valid approach in seeking to replicate the decision processes extant in the supply chain (Lonsdale, 1999).

- Risk management may also be viewed at different levels of aggregation. The focus may be on the risk/performance relationship with an individual member of the supply chain (i.e. dyadic interaction). Alternatively, the concerns may revolve around the portfolio of risk/performance relationships with all members in the chain. The portfolio perspective is not simply an aggregation of the individual dyadic interactions as the performance and risks may counter-balance each other in aggregate terms. It may be entirely consistent for an organisation to continue to trade with partners who increase the risk exposure or reduce potential performance, providing that the other members in the portfolio counter-balance this (March and Shapira, 1987). Other disciplines have successfully developed portfolio approaches combining performance and risk (e.g. Financial Management’s Capital Asset Pricing Model, Sharpe, 1964). 
- $\quad$ Risk itself can be an evasive concept in practice, partially because it is contingent on the context, personality traits and the actions of the participants involved. Decision makers may display bias towards particular preferred outcomes, or focus attention on certain facets of the risk situation even to the exclusion of other pertinent factors, often determined by prior experience, functional orientation or personal interest or preference (Slovic, 1987). Not surprisingly, this results in difficulties in achieving agreement on the risk assessment and evaluation between those involved.

- $\quad$ Risk taking may also portray elements of management conceit as managers 'engage in relatively conscious strategies designed to inflate the perceived riskiness of successful actions,' (March and Shapira, 1987, p.1413).

- It is important to view risk management more from a process perspective than a structural one (Harland et al, 2003). Recognition of the processes involved, internal and external to the organisation and the importance of negotiation, relationship development and trust building are important features towards understanding risk management within organisations.

Risk management in practice needs to find some means of resolving such issues and to achieve greater consistency in its approach. This in itself implies a process of negotiation between the parties engaged in managing the business risks.

\section{Supply Chain Risk Management Framework}

Within the field of Supply Chain Management, an important sub-field of Supply Chain Risk Management is emerging (Paulsson, 2004). Ritchie et al (2000) recognised the potential for all participants and relationships within the supply chain to contribute to managing the risk. This suggests the need to consider the individual relationships with others in the supply chain as well as the aggregate portfolio of relationships with all the suppliers and distributors throughout the chain. The conceptualisation of the risk management process (Figure 1) comprises two levels, the dyadic and the portfolio level, each comprising a set of interdependent activities. The upper half of Figure 1 represents the main elements of the dyadic process, mapping the chain; identifying the risk sources and their nature; defining and measuring the performance and risk consequences; assessing the likely occurrence and consequent outcomes; and finally negotiation and agreement on a collaborative strategy to avoid, modify or mitigate the risks identified. These elements and their sequence correspond with many of the prescribed approaches by others in the field (e.g. Harland et al, 2003; Zsidisin et al, 2004). In normative terms, this process ought to be undertaken for every individual strand (i.e. interconnection) within the chain, although in practice it is likely that management resource availability will 
constrain this to only those perceived as being critical or most vulnerable.

\section{Supply Chain Risk Management Framework Process Elements at Dyadic and Portfolio Levels}

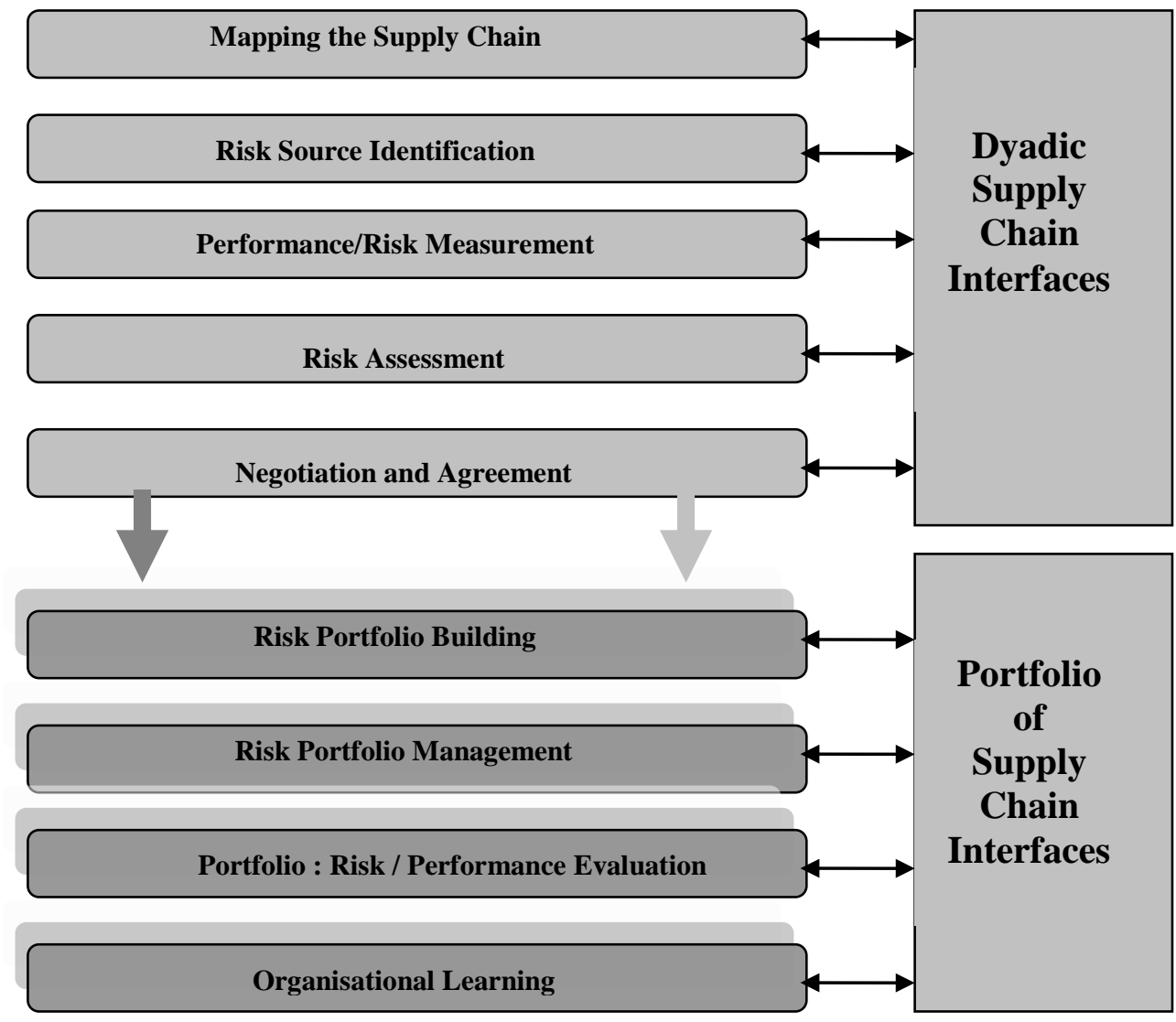

The lower part of Figure 1 emphasises that the organisation is typically managing a portfolio of such individual strands simultaneously, highlighting the issue implicit in other approaches (e.g. Harland et al, 2003; Zsidisin, 2003), that this is a complex, multi-faceted, interactive and highly dynamic management process.

Agency Theory provides an appropriate mechanism to address supply chain relationships and their management, since the approach evolved to describe 'the risk-sharing problem as one that arises when cooperating parties have different attitudes towards risk’ (Eisenhardt, 1989a; p. 57). Essentially, the approach conceives of the relationship between two co-operating parties the 'principal' and the 'agent' (e.g. the manufacturer and its supplier or distributor) as being represented by a 'contract', in which they share an agreement in terms of performance and risk sharing. Melnyk et al (2004) in supporting the contribution of Agency Theory to the field of operations management, emphasise that it is the performance measurement or 'metrics' that are the primary focus of the principal and agent rather than the notion of the 'contract' itself. 
In the Supply Chain context the principal seeks to specify the performance criteria and identify the associated risks in relation to each individual supplier or distributor. The agent will undertake a similar appraisal leading to the negotiation of an agreement (i.e. contract) in terms of performance, risk sharing and rewards. Agency Theory suggests that the principal will engage in the development and implementation of outcome-related performance measures, behaviour-related performance measures, information systems and other control systems to monitor and manage the agent's adherence to the contract. Some of these measures and information requirements may well form part of the negotiation of the contract itself and provide opportunities to renegotiate the sharing of the risks and performance outcomes in the event of any deviance from the contract or the predicted situation. The post-contractual process then becomes one of monitoring, controlling and managing performance and risks. Typically, most businesses will be engaged in a multiple of such agreements, faced with managing a portfolio of agents, both suppliers and distributors. This is represented in Figure 1 as the negotiation and agreement stage in the process.

The risk management processes and activities may involve negotiation on the possible means of avoiding or ameliorating potential risks, agreement on how best to resolve or manage both the likelihood and potential consequences of any risks identified and more generally to establish relationships and communication channels, which may lead to early identification and resolution of new and unforeseen future risks. For example, if the principal is concerned about the agent's (e.g. dealership’s) liquidity as a consequence of taking on the distribution contract, the principal may seek assurances that additional lines of credit have been secured with the bankers in the event of a liquidity crisis occurring. Equally, establishing close working relationships may facilitate the resolution of unforeseen events such as the loss of a key employee to a competitor organisation. This five stage risk management process (Figure 1) will be conducted in relation to each of the individual agents, although the sequence and formalisation of the stages may vary depending on the principal organisation and the nature of the supply chain itself.

The subsequent stages in the process (Figure 1) deal with the aggregation of the individual risk profiles into a portfolio of risks and returns. Providing that the aggregate profile is within acceptable and manageable limits for the principal then this may be a tenable position. However, the principal needs to maintain continuous monitoring of the portfolio as it is likely to be fairly dynamic given the number of variables that may influence the risk and performance parameters both severally and jointly.

The performance anticipated as a consequence of the risk exposure is an integral element and may be measured in terms of sales revenues generated, market share ratios or some other measure of performance. Both the principal and the agent will seek to forecast performance outcomes in relation to the risks 
undertaken. The dynamics of the process are self-evident in terms of the number of parameters likely to influence performance and risk. The risk management process is conceived as a more pro-active rather than re-active one, whose composition and shape may vary depending on the situation. The concluding element of the Framework recognises the importance of organisational learning, both severally and collectively for the participants involved, reflecting the final element of the Balanced Scorecard (Kaplan and Norton, 1996). Indeed, the concept of inter-organisational knowledge management within organisations to complement the concept of value added partnerships, was proposed by Bengtsson and Kock (2000).

\section{Methodology}

The twin approach of conceptual framework development and practice based evidence (i.e. the empirical case study) was viewed as important in bridging the normative and descriptive positions. The practice evidence was gathered from the Principal. Developing the conceptual framework facilitated the application of structure and logic to what may be perceived as a 'messy process' of performance and risk management, often operating in a fragmented, partial and disjointed manner (Zsidisin et al, 2000). Equally, grounding this 'sense-making' in the evidence obtained from the practical processes ensures greater fit between the conceptual framework and practice, enhancing the robustness of the Framework and indicating the direction of future research.

The empirical study examined a single case of an ongoing supply chain situation, which had been established for a number of years but was subject to continuous evolution and change, resulting from changes in the external competitive environment for the chain as a whole and the members of the chain individually. The focus of the study was the processes and metrics employed initially by the Principal (see later section for the description of these six performance/risk profiling elements) and how these evolved over time. Application of the case study methodology was particularly appropriate since 'the focus is on a contemporary phenomenon within some real-life context' (Yin, 1994, p.1), and could be viewed as 'illustrative' (Scappens, 1990), in that the purpose was to explore new and innovative practices adopted by the Principal.

The Study was conducted over a period of three years using a single 'principal' organisation and its 'agents' (dealership network) within the UK. The longitudinal dimension of the Study maps changes in the risk assessment, performance evaluation and management processes, permitting an assessment of the evolutionary development, including the transfer of information and the acquisition of knowledge and learning by all parties. It was also possible to assess how the risk management approach withstood significant strategic changes (e.g. termination of manufacture and assembly in the UK), both within the Principal (the manufacturing organisation) and its agents (the dealerships). 
One member of the research team was employed by the Principal Organisation and was directly involved in the risk management process itself, undertaking the role described by Burgess (1984) as 'participant-asobserver', forming normal working relationships and being openly involved in the data collection process. Adopting the Smith and Dainty (1991) paradigm of closeness to the case enabled patterns to be identified and analysed, paralleling the more conceptual theory building. Although, recognising the issues raised by Burgess (1984), Jorgensen (1989) and Brewer (2000) care was exercised to avoid any potential bias or discrepancies in the data collection, analysis and evaluation of the data. At each stage the observations were corroborated by other documentary evidence such as reports, minutes and memos (Ellram, 1996). Validity being ensured, by a logical and consistent approach to the data collection and analysis (Mitchell, 1983). The usual difficulties encountered by longitudinal studies such as changes in the external and internal contexts, changing personnel and changes in the strategies adopted, mean that care also needed to be exercised in how the evidence may legitimately be generalised. The identities of the Principal Organisation and its dealers have not been revealed on the grounds of commercial confidentiality. Sufficient information is provided to comprehend the nature of the supply chain without revealing individual identities.

The analysis sought to categorise the data using the initial conceptual framework (Figure 1), whilst reviewing and checking for any missing data or apparent inconsistencies. As Baker (1976) argued when analysing a case it is important to identify and ensure the facts and apply judgement to uncertain areas, which are remaining following the factual analysis. Construct validity was achieved through the use of these multiple data sources (Ellram, 1996), and ensuring a logical path from model development, through question formulation to the Case Study summary and a final review with the key informants. Parallel linkages between the research strands, meant that the research process involved “constant iteration” (Eisenhardt, 1989b, p.546). Throughout the empirical research 'theoretical propositions have guided data collection and analysis' (Yin, 1994, p.13) and these are presented subsequently in the paper.

\section{Empirical Case Study}

The evidence from the Study is presented in three stages, the contextual background to the case situation; the initial performance and risk assessment approach; and the Modified Approach - the Standards Programme

\subsection{Contextual Background}

The Principal in this case is a multinational organisation operating in 140 different countries and manufacturing and selling a range of products under a variety of brand names. The worldwide distribution 
network comprises approximately 8,800 independent dealers and distributors though those involved in the present study in the UK and Ireland number 24. The key features of the market and industry context include:

1. Products are all high value agricultural equipment, tractors and associated implements, representing the single most important capital investment on most farms. Increased intensity of farming and the move to larger scale operations, a factor accelerated by the 2001 Foot and Mouth epidemic in the UK, has resulted in a decline in the number of end users, compensated by increasing expenditure frequency and scale. The result is fairly stable aggregate demand but intense competition for market share.

2. Products are wholly manufactured and assembled outside of the UK and imported complete, with an average lead time of 6 to 8 weeks.

3. Stockholding by the principal in the UK is minimal although agents themselves may hold a small number in stock.

4. Increasing frequency of model turnover with new model ranges introduced every 3 years on average, incorporating modest design and added value features, provide the key to product differentiation.

5. Stable dealership network (turnover of 1 or possibly 2 dealerships per year at most), resulting from combination of dealership initiated change (e.g. decision to change to another supplier) and principal initiated change (e.g. termination of agreement due to service quality concerns). Management effort is concentrated on resolving such dislocations and ensuring the end customer has a secure and stable distribution relationship. This approach parallels the conventional risk/performance portfolio approach, exercising a degree of toleration of higher risks and poor performance from individual dealers providing that these are counter-balanced by stronger performance elsewhere in the dealership portfolio.

6. Changes in the marketplace and industry context have consequences for the dealership operations themselves including:

- Customer support and servicing now demands greater availability and mobility (e.g. 24 hour support /servicing provision at their own farms).

- Increased technical expertise and skills required of dealership staff, given the enhanced digital controls in the products.

- Emphasis on new technology and service quality training and management with manufacturer providing subsidised training and dealer supporting through release of staff.

- Labour retention, both within the industry as a whole and within particular dealerships, is an increasing problem given the higher and improving skill levels required and the generally lower labour wage rates in the agricultural industry compared to the automotive sector. 
- Increased attention to managing overheads, especially given the general squeeze on profit margins throughout the industry.

Changes were observed over the period of the study in the processes and interactions, suggesting closer relationships:

- Development of Dealership Business Plans in conjunction with the principal's sales representatives. Bonus payments to the dealership increasingly linked to the achievement of agreed and planned performance and risk outcomes.

- The development of shared Management Information Systems, with the Principal providing regular sales and market share analysis.

In light of this contextual background the Principal initiated a process of performance and risk management of their agents that is described in the following two sections.

\subsection{Initial Performance and Risk Assessment Approach}

At the beginning of the Study, the initial process developed by the Principal sought to profile each individual dealership in terms of a composite assessment of potential risk and planned performance. The profile comprised six elements as described in Table 1:

Performance / Risk Profile

\begin{tabular}{|l|l|}
\hline \multicolumn{1}{|c|}{ Risk Profile Elem } & \multicolumn{1}{c}{ Measures } \\
\hline Brand Commitment & $\begin{array}{l}\text { Brand promotion, loyalty to the principal, pride in the products, promotion of the princip } \\
\text { linked financial and credit products and the presence of a generally supportive and } \\
\text { collaborative culture. } \\
\text { Composite subjective evaluation of these elements. }\end{array}$ \\
\hline Financial Stability & $\begin{array}{l}\text { Reported profits over previous 2 year period; stock valuation (e.g. new equipment and pa } \\
\text { amount owed to the principal; personal asset backing as security for loans (e.g. farm or h } \\
\text { ownership) and the profit generated in relation to the value of current assets. }\end{array}$ \\
\hline Management Quality & $\begin{array}{l}\text { Quality of the senior management; management support and encouragement for a team } \\
\text { approach (e.g. relationship between sales and parts managers); recognition and planning } \\
\text { succession in key management roles; and the presence of normal management practices } \\
\text { as business planning and budgeting. } \\
\text { Composite subjective evaluation of these elements. }\end{array}$ \\
\hline Parts Performance & $\begin{array}{l}\text { Parts sales data used to calculate a crude sales/unit ratio in relation to the total number of } \\
\text { tractors to be serviced in the particular sales area. Assessment of the regular stockholdin }\end{array}$ \\
\hline
\end{tabular}




\begin{tabular}{|l|l}
\hline & $\begin{array}{l}\text { levels, whether they were usually sourced from the principal or other parts suppliers and } \\
\text { maintenance of adequate stock levels. }\end{array}$ \\
\hline Service Performance & $\begin{array}{l}\text { Quality of service benchmarked (implicitly if not always explicitly) against the best serv } \\
\text { performance level found elsewhere in the same sales territory. } \\
\text { Composite subjective evaluation of these elements. }\end{array}$ \\
\hline Customer Satisfaction & $\begin{array}{l}\text { Perceived level of customer satisfaction, although not quantitatively measured, comprise } \\
\text { level/frequency of customer complaints, letters of commendation for service. } \\
\text { Composite subjective evaluation of these elements. }\end{array}$ \\
\hline
\end{tabular}

Each of these elements was assessed by the sales representative(s) using a six-point scale, ranging from 'Dire' (scoring zero) to 'Excellent' (scoring five). The scoring of the individual dealerships was undertaken by a panel of all the field representatives, arriving at a consensus following discussion and debate. Each of these six element scores was aggregated to provide an overall score for the individual dealership. Performance and risk were therefore assessed on a relative scale (i.e. comparing the profile of one dealership in aggregate and on individual element scores) rather than against some objective and measurable criterion or performance/risk benchmark.

Observations on the initial approach to assessing performance and risk include:

1. The value of the approach was the ability to discriminate between the dealerships in terms of performance and risk at either extremes of the scale. Out of the total sample of 24 companies, seven were clearly differentiated from the remainder, three in the bottom quadrant and four in the top quadrant.

2. Differentiation between the remaining 17 companies proved more difficult as the aggregate scores tended to converge into the narrower central range of 2.9 to 3.9, i.e. the mid-point of the scale.

3. Management Quality was consistently scored lower than any other of the six elements in every dealership. The constituent elements - Team Quality, Succession Planning and Business Planning were all typically scored in the lower quartile of the scale. This reflected the principal's concern about the dealerships’ management commitment to both medium and long term planning, highlighting a serious area of future risk that needed to be recognised and addressed.

4. Service Performance and Customer Satisfaction were also rated low across the sample in general, though this may indicate a functional bias in terms of those involved in the assessment process (i.e. the principal's sales representatives). 
5. The process generated a Confidence Ratio, incorporating a simple aggregation of the six elements, designed to differentiate between the weakest and the strongest in terms of performance and those most and least prone to failure i.e. risk from the principal's perspective. There was some ambiguity as to whether the process was generating an ex-post measure (i.e. simply reflecting what is already known) or an ex-ante measure (i.e. predicting potential consequences in terms of vulnerability), the latter providing a tool for risk assessment and management. It is highly probable, for example, that the prior 'knowledge' that distributor A is vulnerable will skew the scoring within each of the elements to reflect this, especially as the measures are essentially subjective and comparative.

6. This initial approach proved valuable in three respects. Firstly, it represented a conscious effort to identify and assess criteria associated with the performance/risk profile of individual dealerships. Secondly, the approach helped to focus attention on those companies posing the greatest risk and engaging consideration of how these may be supported to resolve such risks. Thirdly, it introduced the concept of managing a portfolio of performance and risk situations. Whilst recognising that the approach employed may have several significant flaws, this nevertheless provided an important stage in evolving more robust systems for assessing performance and risk.

It was observed that the Principal took a number of decisions after assessment. Firstly, the termination of a dealership contract. The dealership was part of a large conglomerate and although highly profitable and producing an above average Confidence Ratio (value of 3.0) it scored lowest in terms of Brand Commitment and Customer Perception. The lack of commitment and the associated risks were the primary reasons for terminating the relationship. Two other dealerships were also severely warned about their performance, having scored poorly in Business Planning and Customer Perception. An added concern was their failure to put in place any Succession Planning, posing unacceptable risks for the future of the distribution network as a whole.

Examining this approach from a more strategic perspective suggests consideration of concepts such as the dealership life-cycle and the implications this may have for the aggregate performance and risk evaluation. Although Succession Planning may be a medium to long term risk factor, the absence of this may accelerate the risk exposure. This would become particularly problematic if more than one dealership in the portfolio were exposed in this way.

\subsubsection{A Modified Approach - the Standards Programme}

The intention of evolving locally, a new set of agreed performance/risk standards to profile the dealerships based on the initial findings (Table 1), was overtaken by the development and implementation by the 
Principal's headquarters of a new Standards Programme globally, permitting direct comparisons on performance and risk across the Organisation, comprising:

1. A set of performance standards covering a number of core areas, including General Business, Sales and Marketing and Parts and Servicing.

2. Each core area has a number of components (e.g. 14 for the General Business and 17 for Sales and Marketing) which are assessed by the Principal's sales representatives on a scale from 0 to 4 . With few exceptions these are subjectively-based scores, though some descriptors do provide quantitative guidance or benchmarks.

3. An aggregated score across all core areas is produced for each dealership, assessed as :
i. Below Franchise (scoring less than $40 \%$ )
ii. $\quad$ Franchise (scoring $40 \%$ to $60 \%$ )
iii. $\quad$ Merit (scoring $61 \%$ to $70 \%$ )
iv. Distinction (scoring $71 \%$ plus)

4. The resulting score is discussed with the dealership management, including action plans to correct possible deficiencies. The aggregated points scored is linked to the payment of contractually agreed bonuses, hence there is an incentive for the dealership to perform well.

The new Standards Programme, whilst more comprehensive in performance measurement terms, appeared less focused on the assessment of dealership risk, although many of the criteria or contributory risk factors are contained within the Standards themselves. The emphasis is more towards the performance dimension, seeking to assure minimum standards of performance are achieved and providing financial incentives to perform in excess of such standards. Although providing a mechanism for early identification of potential risk in relation to a particular dealership, there may still be occasions when more detailed risk analysis and exploration is required. This would be especially true if the appraisal across the portfolio of dealerships suggested problems with performance and excessive risk in aggregate.

There is a concern by the Principal that the dealerships themselves may not fully comprehend the nature of some of the Standards nor what the full implications are and how they might best meet them. Thus, developing the knowledge and understanding of the Standards themselves is an important requirement for training of the management within the dealerships.

\section{Supply Chain Risk Management: A Portfolio Management Process}

The empirical evidence from the Case illustrates the move from one method of risk assessment to another and a change in organisational policy, enabling a further iteration of the Framework. The initial conceptual 
framework (Figure 1) was grounded in the literature, utilising this, together with the empirical evidence from the Case, produced a richer framework (Figure 2) from which certain propositions are derived. The upper section of the Framework (Figure 2) identifies the key players, the principal and agents; the primary stages in the risk/performance management process between the principal and the agents; and the outcomes. Two features are particularly relevant to the present discussion. Firstly, the portfolio aspect, reflected in the principal dealing with multiple agents simultaneously (24 in our case study) generating a continuous parallel stream of interactions between the principal and its agents. Secondly, this is a highly dynamic and changeable process of two-way interactions, at the operational, tactical and strategic levels.

Supply Chain Risk Management Framework : Portfolio Management Process

Figure 2

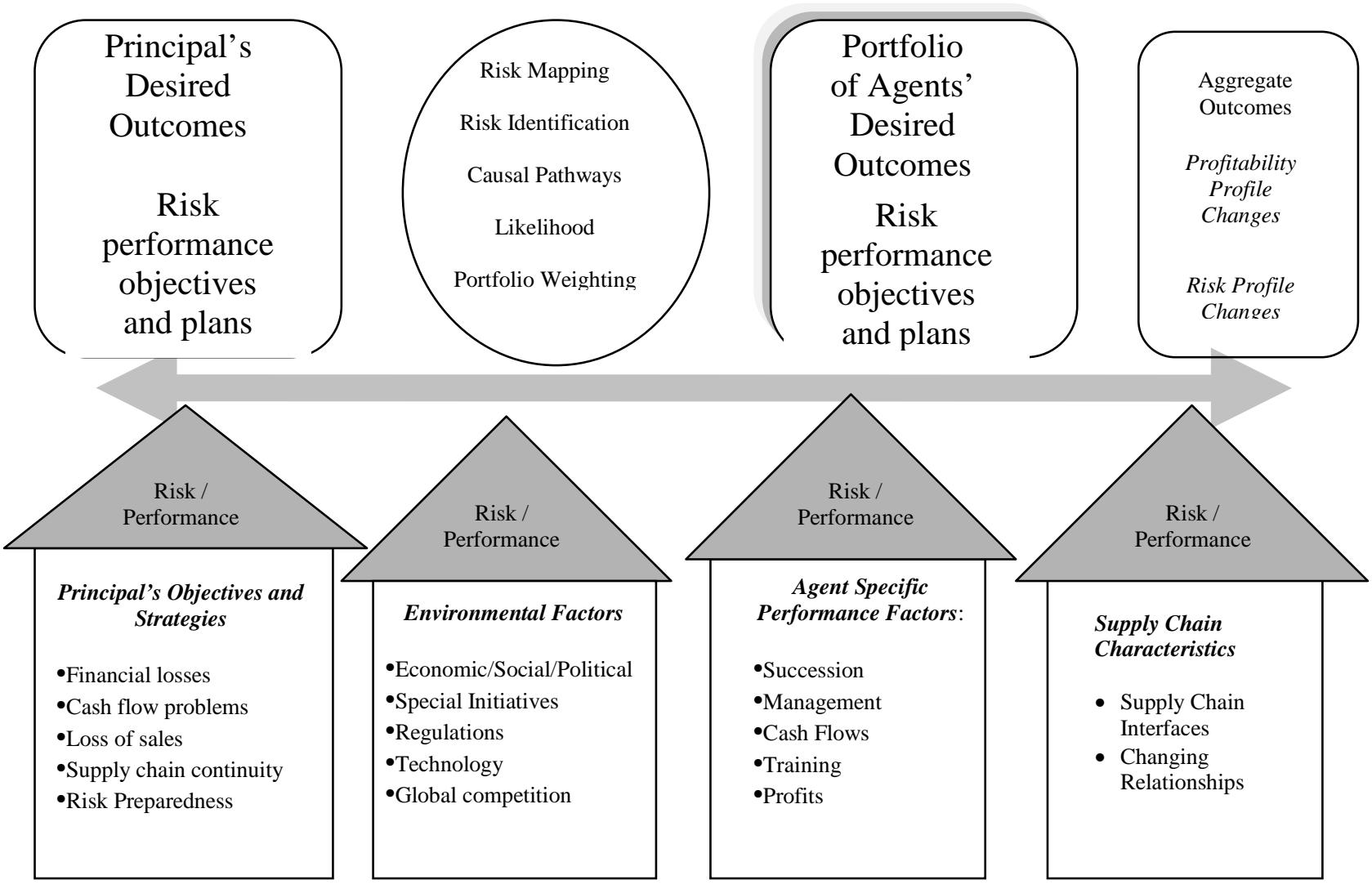

The lower section provides a categorisation of the key factors influencing risk and performance. These risk/performance drivers are grouped into four categories - Principal's Objectives and Strategies, Environmental Factors, Agent Specific Performance Factors and the Supply Chain Characteristics. Some factors may influence all members and stages in the process whilst others may dominate a particular member or stage in the process. Peck (2005) provided a similar classification of risk/performance drivers in assessing 
supply chain vulnerability - Value stream / product and process; physical assets and infrastructure dependencies; organisation and inter-organisational networks and the environment.

Using the Framework (Figure 2), the next stage of analysis was to view the empirical case evidence from three perspectives, principal, agent and shared. Propositions are identified for each of these in turn to focus the discussion and to try and identify generalisations.

\subsection{Principal's Perspective}

Proposition 1 - the principal needs to plan and manage the performance/risk portfolio in aggregate, seeking to balance the distribution in terms of performance and risk across the short to long-term.

In terms of the individual principal-agent interaction, the principal having established its own corporate strategic performance/risk objectives, needs to disaggregate these into more identifiable and measurable components relating to the individual agency. Examples of these in the Case Organisation include brand commitment, financial stability and management quality. Implicit in the setting of performance/risk criteria for agnets is an assessment of the preparedness of the principal itself to accept risk and the nature and scale of these (i.e. risk sharing). Effective management of the portfolio of agents becomes a critical determinant of the likely success of the principal's strategies.

Proposition 2 - the governance of the supply chain relationship requires a continuous process of monitoring and managing performance/risk at the individual agent level, balancing this in the context of a portfolio of such relationships.

The Case illustrates that governance operated at a number of levels. The Principal's sales, stock management and finance functions provided the lower level operational engagement with each dealership, resolving performance and risk issues and incidents on an ongoing basis (e.g. shortage of spare parts). The periodic review, usually monthly, of the performance and risk associated with each dealership was undertaken by all of the sales representatives and the middle management. Such meetings would identify and resolve potential underperformance or emergent risks and initiate actions to resolve these. Ultimately, the annual review conducted by senior management would embrace not only the previous year's performance but the performance plans for the coming year and the associated risks. Decisions at this level would be concerned with significant changes in the strategic risks associated with the 'contract.'

Proposition 3 - as the relationship matures, the emphasis in governance will shift from the more formal outcome based measures of performance towards a more open, transparent and relationship based approach. 
The majority of 24 dealerships had been involved with the Principal for a number of years. It was observed that the more established dealerships enjoyed a closer and more open relationship with the Principal. A degree of 'trust' had emerged between most of the parties, although there remained an underlying recognition of the goal conflict and risk sharing consequences. The essence of the Modified Standards Approach was one that sought simultaneously to provide financial incentives based on outcomes and to build stronger and closer relationships with the agents. The findings of Brindley and Ritchie (2001) reached similar conclusions when investigating the contribution of relationship marketing to building trust in supply chains.

\subsection{Agents' Perspective}

Proposition 4 - the agent in managing their own performance and risk outcomes need to recognise the general needs of the principal and the approaches employed in monitoring and managing their own performance.

The two initial sets of performance/risk drivers provide the context in which the individual agents will operate and be assessed. Factors such as the exposure to liquidity problems, loss of key accounts and the succession of management will all have a potential influence on the performance/risk assessments at different levels. Conflict in relation to performance goals and risk sharing are likely to be in evidence and require resolution. The evidence from the Case suggests that whilst the primary negotiation and resolution of the parameters may occur at the more strategic level, the interpretation and management of these is dependent on subsequent actions at different levels throughout the year. Negotiation to reach a shared understanding of such differences (e.g, profitability, liquidity, management effectiveness, training and development), if not complete agreement on a common perspective was seen to be important in the success of the relationship. Effective risk management should seek to resolve any such significant differences concerning the influencers itemised.

\subsection{Shared Principal and Agent Perspectives}

Proposition 5 - success in managing supply chain performance and risk is dependent on the ability to reach a common shared position on expected performance, risk and risk sharing.

Achieving a common shared position on risk is not only problematic in terms of the dyadic interaction but more difficult in terms of the portfolio perspective. Certain performance/risk drivers will have a fairly universal impact (e.g. global competition, oil price changes), others may impact primarily on the principal (e.g. product safety specifications). Others may impact differentially on individual agents (e.g. regional incentives and assistance, local planning regulations or policies). Differences in perception of the drivers, their causal pathways, likelihood and consequences may lead to differential perceptions rather than common perceptions. The task is to establish a shared understanding and ultimately an agreement, not only on the risks 
but on their consequential impact on performance. Hence, the principal needs to engage in separate negotiations concerning performance and risk with each of its agents.

Proposition 6 - supply chain management operates within a highly dynamic context and the management structures, processes and systems need to reflect this.

The agricultural sector in the UK has experienced very significant disturbances both as a consequence of 'natural' disasters (e.g. Foot and Mouth epidemic), long term sector decline and changes in the supply chain configuration itself. Melnyck et al (2004, p.210) argued that 'these new metrics systems need to be flexible in recognising and responding to changing demands placed on operating systems due to product churn, heterogeneous customer requirements, as well as changes in operating inputs, resources and performance over time.' The empirical evidence from the Case demonstrates this uncertainty and potential for major disturbance in two ways. Firstly, the dealerships were actively seeking to diversify their own strategic portfolio, although this in itself posed the risk that they may be perceived by the principal as lacking commitment and loyalty. Secondly, there is the preparedness of the dealerships to engage in closer relationships with the principal as a means of seeking assurance or protection against the more severe future consequences (e.g. loss of their dealership).

Proposition 7 - the complexity of the supply chain and the interacting variables results in unpredictable outcomes in performance and risk terms. Developing sound supply chain interfaces helps defend the principal and agent from the full consequences of adverse and unpredictable events.

All supply chains are subject to either dislocations or disturbances over time (Peck, 2005), the frequency and severity of their incidence may vary depending on the contextual factors comprising the chain and its members. Developing sound supply chain interfaces in a technical sense (e.g. electronic exchange of sales and production forecasts) and in a behavioural sense (sharing perceptions on risk) may help to prevent or ameliorate the likelihood and the scale of potential negative consequences. Extending this along the vertical chain (e.g. extending to the customer in the case situation) may provide additional assurance against potential risks.

\section{Conclusions}

The evidence from the empirical study over the period of three years demonstrates that the emphasis has moved from being primarily one of operating at arms-length and measuring financial performance to one in which a more comprehensive assessment of risk and performance is undertaken as part of building and maintaining a more intimate relationship between the Principal and the agents. Risk assessment represents an important dimension of the relationship, both at the individual level and in terms of the portfolio of 
dealerships. Assessments of activity levels in succession planning are an example of risks that will influence the relationship both tactically and strategically. There are perceived benefits not only to both partners in the dyadic relationship but more widely to the network as a whole. The increased confidence and trust leading to greater preparedness to share forecasts and strategies results in more stability and enhanced predictability for those further back in the chain.

The structures, processes and measures associated with performance/risk measurement in the Case Organisation may appear to lack refinement and may be challenged on grounds of statistical validity and reliability. However, the Organisation sees merit in the application of such approaches both at the individual and aggregate portfolio levels. Moreover, the commitment of the Principal in the case towards developing and evolving the approach demonstrates the perceived value to the Organisation in defining how best to manage the relationships.

The identification, measurement and evaluation of risk appear often to be an implicit rather than explicit element in the management process. For example, the focus on Brand Commitment in itself is not an evident risk measure, although clearly has implications for future risk and performance. The performance / risk constructs employed in the risk evaluation are possibly more acceptable to the managers and staff as they specifically exclude the term risk and can convey the appropriate actions necessary to effect change. The use of such 'proxy' variables appears to have been well received by both the Principal and the dealerships.

The evidence from the empirical study corroborates the conceptual framework (Figure 2). The emerging propositions provide guidance in terms of the development of risk management in supply chains. Although the focus of the Case has been towards downstream interactions in the supply chain, there is no reason not to believe that they may apply equally upstream (i.e. managing a portfolio of suppliers).

Caution was expressed at the outset as to the degree to which the results from the Study may be generalised, given the evidence emanating from a single case study. What may be concluded, however, is that the integration of the performance and risk factors are critical to understanding the relationships between members of the supply chain. Secondly, as the relationship develops then it evolves in terms of the closeness of the relationship including the preparedness to share and exchange information concerning different aspects of performance and risk. The move towards mutually supportive mechanisms (e.g. management development programmes) is a likely consequence of this closer relationship, again seeking to build confidence, improve performance and reduce risks. Ultimately, the leading partner or principal retains the ability to enforce acquiescence to the agreed performance/risk code on all the other partners. 
The next stages in the research are firstly to continue the investigation of the longitudinal evolution of the relationship in the case organisation and to examine the success of the new approaches to managing the performance and risk outcomes. Secondly, to explore whether the propositions may have wider empirical support, including their application to upstream interactions (i.e. managing a portfolio of suppliers) and thirdly to examine supply chain settings where the power and influence of the principal in relation to the agents may be less dominant. Finally, we would seek to explore more directly the agent's perspective in a more 'grounded approach' seeking to establish the personal, organisational and contextual parameters that influence their responses, essentially seeking to develop a set of contingency variables. Furthermore, the fact that the parent organisation is seeking to apply a common Standards Approach across all of its international operations is itself a fascinating development suggesting that there is the potential to undertake cross-country comparisons.

\section{References}

Adams, J., 1995. Risk, UCL Press, London,.

Baker, M.J., 1976. The written analysis of cases, Quarterly Review of Marketing, 1, 1-6.

Bengtsson, M., Kock, S., 2000, Coopetition in business networks - to cooperate and compete simultaneously, Industrial Marketing Management, 29, 411-426.

Brindley, C.S. and Ritchie, R.L., 2001. Relationship marketing as a solution to entrepreneurial risk, AMA $6^{\text {th }}$ Annual Research Symposium, The Marketing Entrepreneurship Interface, Kingston University, $11-12^{\text {th }}$ January 2001.

Brewer, J.D., 2000. Ethnography, Buckingham, Open University Press.

Burgess, R., 1984. In the Field: an Introduction to Field Research, George Allen \& Unwin, London.

Christopher, M., 2000. The agile supply chain: Competing in volatile markets, Industrial Marketing Management, 29 (1), 37-44.

Christopher, M. and Peck, H., 2004. Building the Resilient Supply Chain, International Journal of Logistics Management, 15 (2), 1-13.

Cox, A., 1999. A Research agenda for supply chain and business management thinking, Supply Chain Management, 4 (4), 209-211.

Croom, S., Romano, P. and Giannakis, M., 2000. Supply chain management: an analytical framework for critical literature review. European Journal of Purchasing and Supply Management, 6 (1), 67-83.

Eisenhardt, K.M. 1989a. Agency Theory: An Assessment and Review, Academy of Management Review, 14.(1), 57-74. 
Eisenhardt, K.M., 1989b. Building theories from case study research, Academy of Management Review, 14 (4), 532-550.

Ellram, L.M., 1996. The use of case study method in logistics research, Journal of Business Logistics, 17 (2), 93-128.

Giannakis, M., Croom, S. and Slack, N., 2004. Supply chain paradigms, in Understanding Supply Chains (eds. Steve New and Roy Westbrook), Oxford, 1-21.

Harland, C., Brenchley, R. and Walker, H. 2003. Risk in supply networks, Journal of Purchasing and Supply Management, 9, 51-62.

Hendricks, K.B. and Singhal, V.R. 2003. The effect of supply glitches on shareholder wealth, Journal of Operations Management, 21, 501-522.

Jorgensen, D.L., 1989. Participant Observation: A Methodology for Human Studies, Newbury Park, CA, Sage.

Juttner, U. 2005. Supply Chain Risk Management - Understanding the business requirements from a practitioner perspective, International Journal of Logistics Management, 16 (1),120-141.

Kaplan, R.S., Norton, D.,1992. The balanced scorecard measures that drive performance. Harvard Business Review, January/February, 71-79.

Kaplan, R.S., Norton, D.,1996. The balanced scorecard. Harvard Business School Press, Boston, MA, USA.

Lee, H.L., Padmanabhan, V. and Whang, S., 1997. Information distortion in a supply chain: the bullwhip effect, Management Science, 43 (4), 546-558.

Lewis, M. A. 2003. Cause, consequence and control: towards a theoretical and practical model of operational risk, Journal of Operations Management, 21, 205-224.

Lonsdale, C. and Cox, A., 1998. Outsourcing : A Business Guide to Risk Management Tools and Technique, Earlsgate Press, London.

Lonsdale, C., 1999. Effectively managing vertical supply relationships : a risk management model for outsourcing, Supply Chain Management: an International Journal, 4 (4),176-183.

March, J.G. and Shapira, Z., 1987. Managerial Perspectives on Risk and Risk Taking, Management Science, 33 (11), 1404-1418.

Melnyk, S.A., Stewart, D.M. and Swink, M., 2004. Metrics and performance measurement in operations management: dealing with the metrics maze, Journal of Operations Management, (22), 209-217.

Miles, M.B. and Huberman, A.M., 1994. Qualitative Data Analysis: an Expanded Sourcebook, $2^{\text {nd }}$ Edition, Sage Publications, London.

Mills, J.F. and Camek, V., 2004. The risks, threats and opportunities of disintermediation, International Journal of Physical Distribution and Logistics Management, 34 (9), 714-727. 
Mitchell, J.C., 1983. Case and situation analysis, The Sociological Review 31, cited in Smith and Dainty eds., 1991, The Management Research Handbook, Routledge, London.

Nassimbeni, G., 1998. Network structures and co-ordination mechanisms: A taxonomy, International Journal of Operations and Production Management, 18 (6), 538-554.

Paulsonn, U, 2004. Supply Chain Risk Management, in Clare Brindley (Ed.), Supply Chain Risk, Ashgate, Hampshire, England, 79-96.

Peck, H. 2005. Drivers of supply chain vulnerability: an integrated framework, International Journal of Physical Distribution and Logistics Management, 35 (4), 210-232.

Ritchie,R.L and Brindley C S, 2000. Disintermediation, disintegration and risk in the SME global supply chain, Management Decision, 38 (8),575-583.

Ritchie,R.L and Brindley C S, 2004. Risk characteristics of the supply chain - a contingency framework, in Clare Brindley (Ed.), Supply Chain Risk, Ashgate, Hampshire, England, 28-42.

Ritchie, R.L. and Marshall, D.V., 1993. Business Risk Management, Chapman Hall, London.

Ritchie,R.L., Morris, J. and Brindley, C.S., 2000. Supply chain management : new challenges for the new millennium, Control Journal of the IOM, July-August, 24-26.

Scappens, R.W., 1990. Researching management accounting practices: the role of case study methods, British Accounting Review, 22, 259-281.

Sellen, W. and Soliman, F., 2002. Editorial- Operations in today's demand chain management framework, Journal of Operations Management, 20, 667-673.

Shapiro, J., 1998. Bottom-up versus top-down approaches to supply chain modelling, in Quantitative Models for Supply Chain Management, Kluwer Academic Publishers, Dordrecht, 739-759.

Sharpe, W.F., 1964. Capital asset prices : a theory of market equilibrium under conditions of risk, Journal of Finance, 19, 425-442.

Slovic, P., 1987. Perception of risk, Science, 236, 280-285.

Smith, N.C. and Dainty, P., 1991. The management research handbook, Routldege, London.

Svensson, G., 2002. A conceptual framework of vulnerability in firms' inbound and outbound logistics flows, International Journal of Physical Distribution and Logistics Management, 32 (2), 110-134.

Yates, J.F. and Stone, E.R., 1992. Risk Appraisal, in Yates, J.F. (Ed.) Risk-Taking Behavior, John Wiley \& Sons, New York, NY.

Yin, R.K., 1994. Case Study Research : Design and Methods, Sage, Newbury Park, CA.

Zsidisin, G. A. 2003. A grounded definition of supply risk, Journal of Purchasing and Supply Management, 9, 217-234. 
Zsidisin, G. A. , Panelli, A. and Upton, R., 2000. Purchasing organisation involvement in risk assessments, contingency plans, and risk management: an exploratory study, Supply Chain Management: An International Journal, 5 (4), 187-197.

Zsidisin, G. A. , Ellram, L.M., Carter, J.R. and Cavinato, J.L., 2004. An analysis of supply risk assessment techniques, International Journal of Physical Distribution and Logistics Management, 34 (5), 397-413. 